Volume 9. No. 9, September 2021

International Journal of Emerging Trends in Engineering Research

Available Online at http://www.warse.org/IJETER/static/pdf/file/ijeter10992021.pdf

https://doi.org/10.30534/ijeter/2021/10992021

\title{
Product Re-Engineering by Topology Optimization for Forged Component
}

\author{
Sagar S. Kaldhone ${ }^{1}$, Sagar U. Sapkal ${ }^{2}$ \\ ${ }^{1,2}$ Department of Mechanical Engineering, Walchand College of Engineering, Sangli, India. \\ ${ }^{1}$ sagarkaldhone@yahoo.in \\ ${ }^{2}$ sagarus1201@gmail.com
}

Received Date : August 04, 2021 Accepted Date : August 24, 2021 Published Date : September 07, 2021

\begin{abstract}
Optimization tools are used when a set of objectives is used to find the best alternative proposed design. Topology optimization adds a whole new level of process of developing creative design space. The objective of topology design is to obtain a material distribution inside a given design space that is optimum in this aspect. Material is rearranged and elements that are not necessary from an objective point of view are eliminated throughout the optimization process. For Topology optimization of the forged component which is selected from industry which is steering knuckle assembly is optimized and presented in this study. For topology optimization, platform such as $3 \mathrm{D}$ experience is used to simulate the part. A number of modules from 3D experience is used for FEA analysis, mesh-smoothening techniques and creating parametric geometry in terms of shape and explored in way to produce the topology geometry more functional. Functional Generative Design module is used for topology optimization. From this study overall weight reduction is achieved after using the finite element method to analyze a steering knuckle assembly and performing topology optimization. And the part is optimized in terms of shape and for further suitable manufacturing process. According to the result of this research, 64\% relative weight reduction is achieved in respect to a given target is $50 \%$. The original weight of the knuckle was $843 \mathrm{gm}$. however it has since been reduced to $513 \mathrm{gm}$. As a result, the cost of knuckle is lowered.
\end{abstract}

Key words: Topology Optimization, 3D Experience, Functional Generative Design

\section{INTRODUCTION}

Topology Optimization is used to solve practical design problems of components or systems with conventional Forging, casting, and machining are examples of manufacturing processes. Subtractive processes are those where the part is produced by material removal and formative processes include the part produced by a mould. By limiting the topology to feasible design or by simplifying the unconstrained optimization these constraints are included in the actual optimization [1]. Usually, the former of these methods is preferred, but all constraints cannot be included with ease in the optimization process. In structural mechanics, topology optimization has become one of the most popular study areas, because (a) It necessitates the use of unique mathematical and numerical concepts. And (b) it saves a lot more money than optimizing the form or size. Despite the fact that the quantity of publications dealing with (i) new methodology, (ii) new mechanical issues, and (iii) The number of new commercial applications of topology optimization is astonishing, yet there are certain basic problems in this subject that need to be addressed [2]. Because the correctness and precision of techniques have not been completely analysed, Factories of the Future will be utilizing more and newer technology, advanced manufacturing methodologies; eliminating waste and enhancing efficiency. To achieve these objectives, manufacturers are increasingly using new technologies, including Robotics, Additive Manufacturing. The Additive manufacturing 3D Printing allows manufacturing of parts of intricate shape with minimal material requirements and still meeting desired strength expectations [3].

Topology optimization workflow

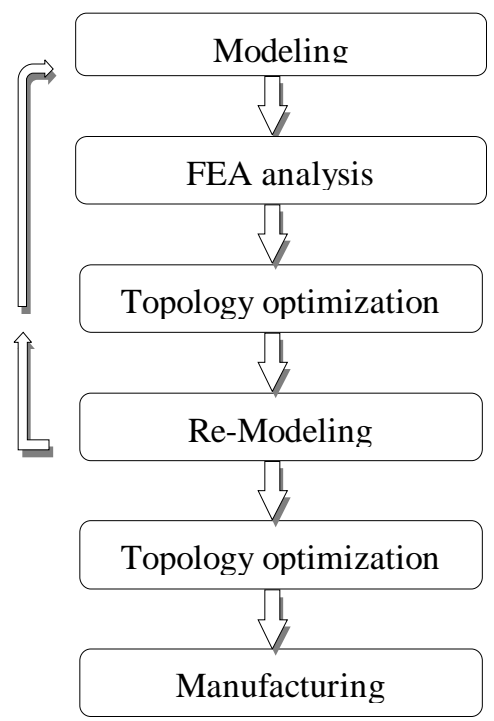


Topology optimization is a method of optimizing material arrangement and structure inside a given 3D geometrical design space according to a set of user-defined rules. The objective is to mathematically describe and optimize for external pressures, boundary conditions, and limitations in order to maximize the system performance. These can help to determine what type of tools needed for modeling of parts [4].

For material selection, there is a material pallet available for selection of various materials and you can add material here with your material properties. In order to conduct a simulation study or create a digital model, meshing is frequently used to split the model into cells which is done in mesh creation module [5].

Topology optimization is used to create a new optimized structural design that is lighter and more rigid. Based on the available design space structure. Topology iteratively removes material and redistributes material in the topology optimization process. Additional cost savings could be achieved due to the excellent new structural design, material savings, easier transportation and assembly processes. Now optimized part is ready for manufacturing [6].

Jian et al [1] in an internal combustion engine, the crankshaft is one of the most critical components. Using Pro/ENGINEER software, a three-dimensional model of a 380 diesel engine crankshaft was constructed in this research. The deformation and stress condition of the crankshaft were investigated using the ANSYS finite element analysis (FEM) software. After that, the Pro/E model of the crankshaft was loaded into the ANSYS programme by Shenoy and Fatemi et.al [2] Optimization of the topology of forged steel connecting rod for weight and manufacturing cost, taking current advances into consideration. However, the optimization performed here is not really mathematical in nature, because mass reduction, production feasibility, and cost reduction are all part of the optimization Klarbring et al [3] perform structural optimization on a single product, this study went on to discuss product optimization in which size, shape, and topology are all taken into account at the same time. Another significant feature of this technique is that the optimal topology and load transfer through a single product may be compared to what is best if the product must be part of a family. To reduce stiffness in the direction of deformation, the topology optimization approach is used. The designs are then evaluated and compared to a conventional regular honeycomb structure as well as a zero Poisson's ratio structure by Lulu C. et al [4]. The crankshaft is responsible for converting the piston's return action into spinning motion. Crankshafts have a shaft component that resonates inside the primary bearings, crankpins are connected to the large ends of connecting rods, and crank palms or web are used to link the crankpins as well as shaft considerations by Sandeep et al [5]. The goal of the project is to format and produce a crankshaft for a four-cylinder IC engine utilising theoretical calculations in the format area for Aluminium alloys 6061 and commercial enterprise grade by Mukherjee et al. [6] The effects of different punch structure, maximum liquid pressure and the radius of the die corner on the forming quality of half-three-way tube parts were compared and analysed [7]. The production period and costs can be reduced by using the optimum process parameters. The validated mathematical framework developed. It was proposed that utilising thinner layers and a quicker scanning speed, refinement of the solidification microstructure by tight spacing of the dendrite arms may be accomplished for dendritic growth. The influence factors of the forming process were studied based on the method of numerical simulation Wenyuan .et al [8]. The final design had a mass of $0.536 \mathrm{~kg}$, a reduction of $36 \%$. FE analysis indicated that the component had maximum von-Mises stress of $265 \mathrm{MPa}$ and maximum displacement was $0.32 \mathrm{~mm}$, a $28 \%$ increase on original design. The topology interpretation stage was completed in approximately 20 hours by Wang et al. developed an integrated optimum design technique using component level topology optimization and parametric system optimization for lightweight serial robots with 6 degrees of freedom optimise connecting rods for weight and cost reduction Anis et al [9]. FEA was used to determine the stiffness matrices of the major structural linkages. The goal volume was set at $55 \%$ of the design space, and topology optimization resulted in a reduction in deformations while maintaining a nearly identical total mass by Zhenga et al [10]. A topology optimization issue is often formulated using a well-defined problem setting. Pre-processing is evident in both the design domain form and the boundary condition. Optimization with multiple choices of design domains or boundary conditions has to be performed with multiple runs of the algorithm to make the best choice among the selective problem setups zhou et al [11]. To increase the topology's optimality, the mesh must be improved, and more fine details must emerge. These details would not be created if they were smaller than the AM machines' minimum feature size. Furthermore, because to the manufacturing limitation, these details may result in the creation of supports, which was unavoidable. As a result, the mesh had to be redefined and the geometry had to be optimised for self-supporting by Walton [12]. The primary goal of this research was to improve single-cylinder diesel engine connecting rods. As a result, our research focused on two topics: static load and dynamic load analysis of connecting rods Khillare and Kamble et al [13] and 3D experience platform [14].

\section{FORGING AND PART SELECTION}

Forging is one of the earliest manufacturing processes. It creates parts and components that are more reliable than machined or cast parts. The interior grain structure of metal deforms throughout the forging process to get the shape and size of the part or component [7]. And proper selection of forged component for topology optimization from the industry is done with his working and loading condition. The name of the forged component selected for topology 
Sagar S. Kaldhone et al., International Journal of Emerging Trends in Engineering Research, 9(9), September 2021, 1266 - 1270

optimization is the steering knuckle and details of that part are given in below which is sued for get desired optimized part.

\subsection{FORGING}

Forging is a metal-shaping process in which metal is shaped by applying compressive forces. The punches are delivered with a hammer or a dice. The most common methods are used to define the on temperature at which forging is done are cold forging, warm forging, and hot forging [8]. In most cases, the metal is heated in a forge. Pre-forged metal begins with ingots, which are metal blocks that come in a various shape and sizes depending on the component to be manufactured. These ingots are heated to a near-molten temperature, which allows the metal to keep its form to get desired shape with force. The heated ingot is edged and blocked with a press or hammer to produce a forged component pressed between the closed dies. This is the point at which the metal begins to take on the general form of the finished product [9].

Forgers can enhance the strength of the finished product by deforming and improving the grain flow inside the metal by cooling of the metal. The flash or extra metal that flows outside of the dies is a significant aspect of impression die forging. The flash hardens and cools quickly, making it stronger than the metal in the dies. This pushes the metal in the dies to fill any holes entirely. Machining and other surface treatment operations are conducted after a forged product has gone through the pressing process to increase the dimensional accuracy of the forged product. Surface treatment can be used to increase corrosion resistance and the finished forged product's quality. Annealing, normalization, tempering and quenching such heat treatment are used [10].

\subsection{PART SELECTION AND CAD MODELLING}

A steering knuckle, also known as an upright, is the portion of the suspension system that houses the wheel hub or spindle and connects it to the suspension and steering components. Steering knuckle is most important part in vehicle assembly but it has less studied in topology optimization so that's why $i$ have selected this part for optimization. To generate a CAD model in 3D experience for topology optimization, we must first utilize CATIA component design. After that, for stress analysis, static analysis is a module that may be used to do stress analysis we may utilize the generative functional design module for real topology and concept generation after a successful mesh construction [11]. Figure 1 shows the CAD model of selected product for topology optimization

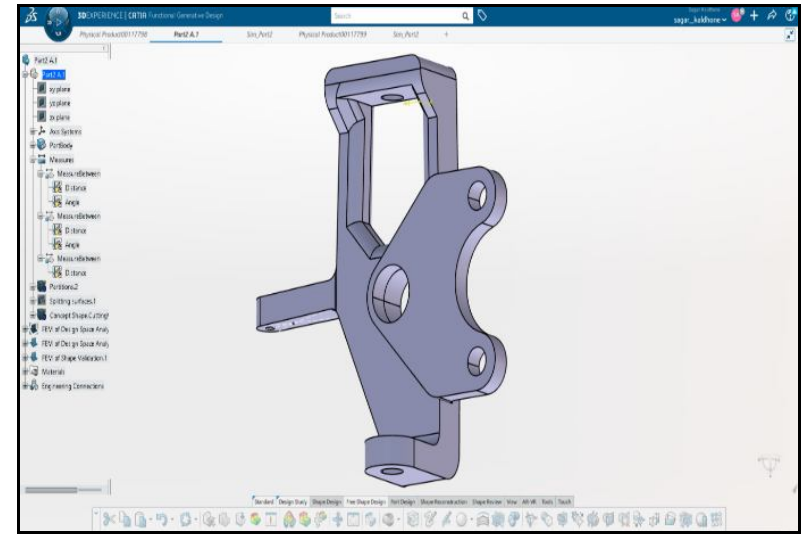

Figure -1: CAD model of steering knuckle

\subsection{MATERIAL: AUSTENITIC CR-NI STAINLESS STEEL}

$\mathrm{Cr}-\mathrm{Ni}$ steel is generally used in knuckle assembly, due to its high impact strength, high corrosion resistance and temperature resistance. It is mostly used in Automobiles industries such as light passenger trains, aviation industries and medical applications. It is also use in energy generation plant and metal 3D printing [12]. Table 1, shows the material properties of Austenitic Cr-Nr stainless steel.

Table -1: Material Properties

\begin{tabular}{|c|c|c|c|}
\hline \multicolumn{4}{|c|}{ Preparation of Austenitic Cr-Ni stainless steel } \\
\hline Density & $\begin{array}{c}0.289 \\
\text { lb./in }\end{array}$ & $\begin{array}{c}\text { Hardness, } \\
\text { Brinell }\end{array}$ & 123 \\
\hline Hardness, Rockwell B & 70 & $\begin{array}{c}\text { Hardness, } \\
\text { Vickers }\end{array}$ & 129 \\
\hline $\begin{array}{c}\text { Ultimate Tensile } \\
\text { Strength }\end{array}$ & $\begin{array}{c}505 \\
\mathrm{MPa}\end{array}$ & $\begin{array}{c}\text { Yield, } \\
\text { Tensile } \\
\text { Strength }\end{array}$ & $215 \mathrm{MPa}$ \\
\hline $\begin{array}{c}\text { At the Break point } \\
\text { Elongation }\end{array}$ & $70 \%$ & $\begin{array}{c}\text { Elasticity } \\
\text { Modulus }\end{array}$ & $200 \mathrm{GPa}$ \\
\hline Poisson's Ratio & 0.29 & $\begin{array}{c}\text { Modulus of } \\
\text { Shear }\end{array}$ & $86 \mathrm{GPa}$ \\
\hline
\end{tabular}

\subsection{FEA ANALYSIS}

It is a computer-based approach that divides geometry into elements and connects a set of equations to each other, which are then solved concurrently to assess the overall system's condition. Loading \& Boundary Conditions: Upper wishbone mounting provision-The uniform force of $923 \mathrm{~N}$ which is on $\mathrm{X}$-direction applied on this upper wishbone mounting provision. Calliper Mounts No-The remote torque of 248.8 $\mathrm{Nm}$ which is on Y-direction is applied on this calliper mounts no 1. Calliper Mounts No 2-The remote torque of $288.8 \mathrm{Nm}$ 
which is on Y-direction is applied on this calliper mounts no 2.Diameter-The remote torque of $248.8 \mathrm{Nm}$ on Y-direction. Below wishbone mounting provision-The uniform force of $923 \mathrm{~N}$ which is on Y-direction applied on this below wishbone mounting provision. Position for holding steering rack-The force of $150 \mathrm{~N}$ applied on this position [13].

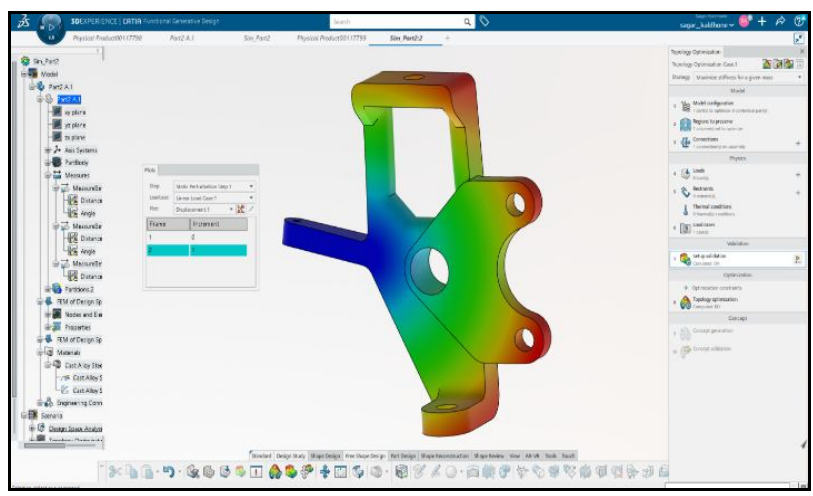

Figure -2: Finite Element Analysis of steering knuckle

It may be used to solve problems with complicated geometry, loads, and material characteristics when a precise analytical solution is difficult to find. The most common applications are structural, thermal, and fluid analysis, but it may also be used for other types of analysis and simulation.In figure 2 shows FEA analysis of steering knuckle on 3D experience. In order to include FEA into your design, along with model geometry, design dimensions, and material characteristics, it is required to determine what to be achieved in terms of increased strength and decreased mass [14]. It is signify that our design space is getting the design right to optimization.

\section{TOPOLOGY OPTIMIZATION OF KNUCKLE}

Topology optimization is a strategy for dividing the simulation domain into regions that can be maintained or eliminated. The main goal of this study is to minimize the total weight of the knuckle assembly. The topology optimization approach used in this study results in the optimum structural shape of the vehicle's knuckle component with the maximum stiffness, while taking into account the amount of mass that will be saved from the initial design space.

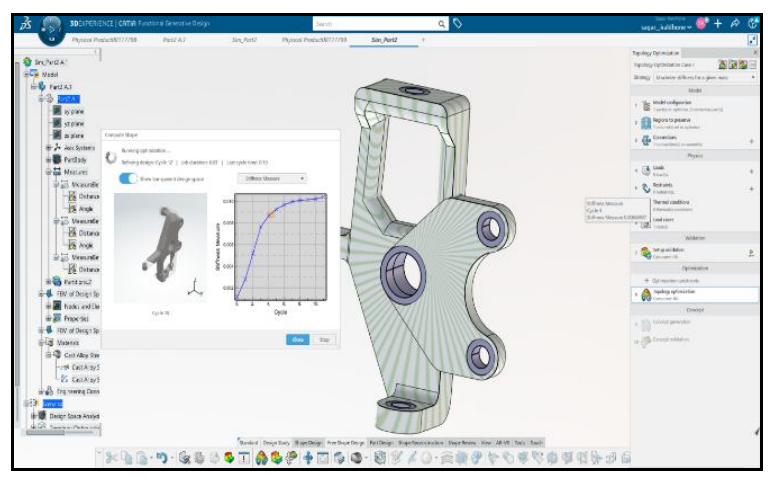

Figure -3: Optimization cycle
Figure 3 shows Optimization cycle while performing topology optimization. Optimization is carried out in 38 cycles. The entire sequence of techniques for undertaking topology management optimization research is provided, taking into account the constraints imposed by the steering knuckle assembly component construction features and manufacturing technology. It can utilize material distribution layout methods to identify the best layout of a system given a design space, loads, boundary constraints, and consistency. The key issue is how to distribute material volume throughout domain space in order to reduce weight. The configuration is now ready for a $50 \%$ run optimization with $50 \%$ mass constraints for validation.

It is required to validate whether the obtained part can be replaced. After successful topology optimization of knuckle assembly in 3D experience we get new design space where material layout is adjusted by software and new design concepts are given. There is a cutting value option which can be employed to reduce percentage volume of the material that is required to remove as per design space given. During validation by using FEA, Comparison shows the component is rearranged with respect to shape and size but strength is same.

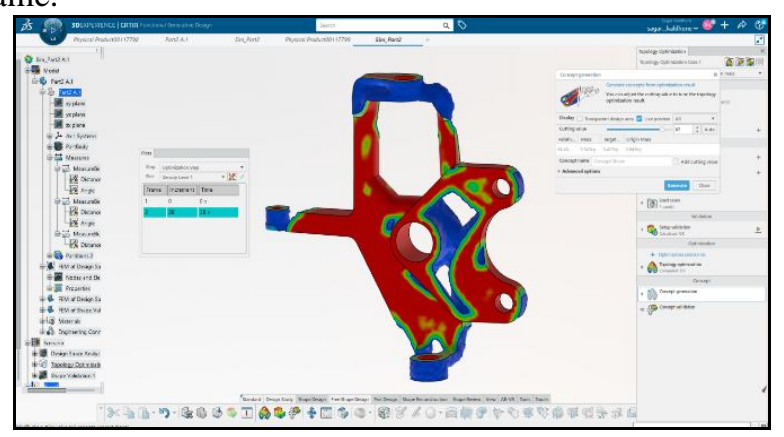

Figure -4: Optimization density level $87 \%$ cutting value

After validating the optimized product it is seen that, $87 \%$ cutting value gives optimized design space. Above Figure 4 shows, $87 \%$ cutting value for material removal.

\section{RESULTS AND DISCUSSION}

The 3D experience simulation's embedded method can be successfully applied to the 3D component of the knuckle assembly. Another factor to examine the findings of the static stress analysis and nodal displacements and various such FEA plots for minimum principle stress, elastic strain plot, Maximum principle stress and von misses stress plot. The calculated values are based on the complete optimized model, which may contain porous components that are less stiff than fully dense elements; massage is shown according to the simulation results section of 3D experience. The highest von misses stress achieved in this topology optimization research is $1.82 \mathrm{e}+10\left(\mathrm{Nm}^{2}\right)$, and the greatest nodal displacement obtained is $8.21(\mathrm{~mm})$. The factor of safety on the deformation scale is 1.94 . This is plainly impossible to do through physical 
Sagar S. Kaldhone et al., International Journal of Emerging Trends in Engineering Research, 9(9), September 2021, 1266 - 1270

prototyping for knuckle. Generative concept for optimizing cutting value $87 \%$ out of $100 \%$ is obtained, $64 \%$ relative weight reduction when target is fixed at $50 \%$ weight equal to 422 grams out of 843 grams. In this optimization process we got 513 grams optimized product. The overall weight of these parts was reduced by around $35.58 \%$ after using the finite element method to analyse a steering knuckle assembly and performing topology optimization.

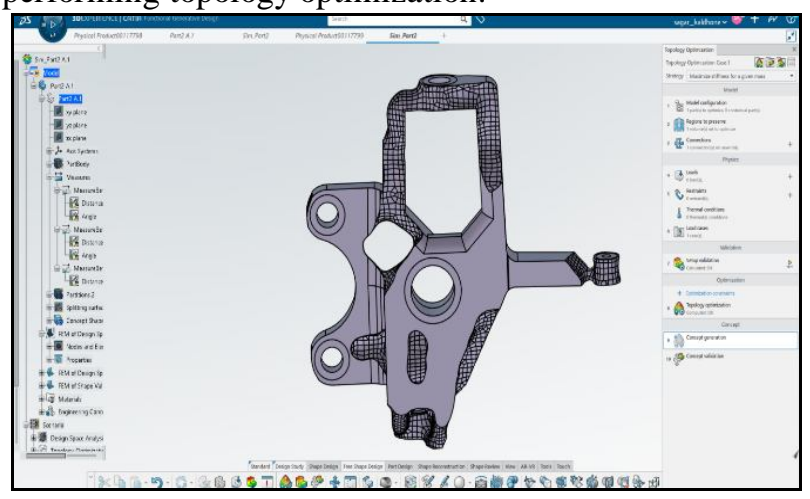

Figure -5: Optimized forged product after refinement

In Terms of shape and size the optimized steering knuckle product is smoothed for further suitable manufacturing process. Due to reduction in weight of optimized knuckle the manufacturing cost will also get reduced. Generative concept for optimizing cutting value $87 \%$ out of $100 \%$ is obtained, $64 \%$ relative weight reduction when target is fixed at $50 \%$ of total weight. Above figures 5 show, the topology optimized part in 3D experience with smooth model and gives final optimized results for forged component, which is ready for further manufacturing.

\section{CONCLUSION}

From this study it is concluded that, $64 \%$ relative weight reduction is done with respect to given target $(50 \%)$.Initial weight of knuckle was $843 \mathrm{gm}$ which is reduced to $513 \mathrm{gm}$. Hence the cost of knuckle is reduced. The calculated values are based on the complete optimized model, which may contain porous components that are less stiff than fully dense elements. To get more realistic solutions for weight reduction of this component the multi-objective optimization can be implemented and manufacturing cost can be reduced by topology optimization.

\section{ACKNOWLEDGEMENT}

The authors would like to acknowledge the support from, La Foundation Dassault's System to provide the facility of 3D experience platform under product innovation lab at Walchand College of Engineering, Sangli.

\section{REFERENCES}

[1] Meng jian et al, "Intension Analysis of 3-D Finite Element Analysis on 380 diesel crankshafts", International Conference on Computational and Information Sciences, (2018).
[2] Pravardhan S Shenoy and Ali Fatemi, "Connecting Rod Optimization for Weight and Cost Reduction",SAE International (01) pp 997-2005.

[3] Torstenfelt and Klarbring, "Conceptual optimal design of modular car product families Using simultaneous size, shape and topology optimization" Finite Elements in Analysis and Design, volume 43 (2007) pp. 1050-1061.

[4] Lulu C, Xing S, Y Dai, T Wang, Lei Z, "Investigation on the mechanical properties of topologically optimized cellular structures for sandwiched morphing skins", Composite Structures, pp-250-255, 2020.

[5] Amrutham Sandeep, Mengu Vijay John, S.P. Jani, "Theoretical modelling and analysis of a four-wheeler crank shaft by different aluminum alloys", Selection and peer-review under responsibility of the scientific committee of the International Conference on Advances in Materials Research,pp 2214-7853, (2019).

[6] Mukherjee $\mathrm{T}$ et al, "Heat and fluid flow in additive manufacturing-Part II: Powder bed fusion of stainless steel, and titanium, nickel and aluminium base alloys", Computational Materials Science, 150, pp. 369 - 380, 2018. [7] Book Reference: "Some Basic Issues of Topology Optimization", Computational Structural Mechanics, pp 402-475_ January 2018. [8] JUNYU FU et al, "Topology Optimization with Selective Problem Setups", Digital Object Identifie , 10.1109/ACCESS.2019.

[8] Lingyun Zhanga, Huan Liub and, Wenyuan Wang "Numerical simulation and analysis of hydro mechanical deep drawing process for half-three-way tube", 13th Global Congress on Manufacturing and Management, volume 174 (2017) pp524 - 529.

[9] Assad Anis et al, "Design analysis and optimization of a crankshaft of a tractor", International Journal of Advanced Engineering and Technology, Volume 1; Issue 4; (September 2017); pp. 11-13.

[10] W Zhenga, Y Wanga, Y Zhenga, D Dab, "Efficient topology optimization based on DOF Reduction and convergence acceleration methods", Advance in engineering software, volume 143, pp 965-978(2020).

[11] Jihong Zhou et al, "review of topology optimization for additive manufacturing Status and challenges", Chinese Journal of Aeronautics, (2020).

[12] Walton and Moztarzadeh , "Design and development of an additive manufactured component by topology optimization", Advance in engineering software Procedia CIRP, volume 60, pp. 205 - 210, 2017.

[13]Siddheshwar K. Khillare, Avinash H. Kamble, "Connecting Rod Optimization for Weight and Cost Reduction", International Research Journal of Engineering and Technology (IRJET) e-ISSN, Volume: 07 Issue: 08 Aug 2020.

[14] Satvik Nirwal and Ravi Katukam, "An approach for Coupling FEM \& Molecular Dynamics", International Journal of Emerging Trends in Engineering Research (IJETER), Vol. 3 No.10, and Pages: 07 - 19 (2015). 